\title{
Location-allocation model for food industrial using fuzzy criteria: A case study of dairy industry
}

\author{
Zahra Esfandiyari $^{\mathrm{a}^{*}}$, and Soheil Sadi-Nezhad ${ }^{\mathrm{a}}$
}

${ }^{a}$ Department of Industrial Engineering, Science and Research Branch, Islamic Azad University, Tehran, Iran

\begin{tabular}{|c|c|}
\hline A R T I C L E I N F O & ABSTRACT \\
\hline $\begin{array}{l}\text { Article history: } \\
\text { Received October } 252010 \\
\text { Received in revised form } \\
27 \text { February } 2011 \\
\text { Accepted } 28 \text { February } 2011 \\
\text { Available online } \\
28 \text { February } 2011 \\
\text { Kevwords: }\end{array}$ & $\begin{array}{l}\text { A good facility layout plays an important role on increasing the profitability of a production } \\
\text { unit. A good location needs to meet different criteria such as the distance between the plants } \\
\text { and the places to reach raw materials, customers, etc. In this paper, we proposed a multi criteria } \\
\text { decision making problem to locate a suitable dairy plant. We assume that all factors influencing } \\
\text { the plant involves uncertainty and proposed fuzzy numbers to handle the uncertainty associated } \\
\text { with all input parameters. We apply the method for a real-world case study of dairy production } \\
\text { unit and analyze the results of our proposed model. }\end{array}$ \\
\hline
\end{tabular}

Positioning

Facility layout

Dairy industries

Fuzzy criteria

(c) 2011 Growing Science Ltd. All rights reserved.

\section{Introduction}

Layout planning plays an important role on increasing the efficiency and profitability of manufacturing systems such as food and dairy industries. There are different criteria for assessing a good production layout such as weather condition, vicinity to raw materials and target market, etc. Van Donk and Gaalman (2004) presented an approach for hygienic layout design of a foodprocessing plant, which can be used for production engineering and design for food processing companies facing a large number of product changes. Oppen and Ryan (1985) studied a procedure to determine an appropriate regional allocation of research resources to mandate crops in mandate regions. Bindi et al. (2009) proposed a method for delivering the order of food products to reduce the cost of transportation. Jin and Tokunaga (2007) investigated a survey for Japanese investment on China's food industry and reported that wages and distance to Japan were the most important factors for investment decision. There are different criteria involved with facility location problems. Singh and Singh (2011) presented a three-level analytical hierarchy procedure (AHP) based heuristic method for a multi-objective facility layout problem. Their approach consists of three levels where the first level applies AHP to generate paired comparison matrices, the consistency of matrix, to

* Corresponding author. Tel: +98 09113706177

E-mail addresses: zahra_esfandiyari62@yahoo.com (Z. Esfandiyari ) 
convert inconsistent matrices into consistent ones and then generates a qualitative objective matrix. The second level applies normalization procedure to normalize matrices of qualitative and quantitative objectives and the third level computes the objective weight for qualitative and quantitative objectives. Huda and Chung (2002) explained that there are many high-speed, minute components, flow oriented manufacturing processes in the food industry and they need the transformation of a product from a fluid state into distinct packages. Therefore, they provided a simulation technique to analyze the system. Facility layout problems can be solved using fuzzy logic and there have been tremendous efforts on using this fuzzy numbers to handle uncertainty (Grobelny, 1987; Dweiri, 1999; Drira et al., 2007). In this paper, we present a mathematical model to locate a facility based on the minimization of Euclidian norm. The proposed model of this paper studies different characteristic of the optimal solution and using the fuzzy numbers analyze them, carefully. The organization of this paper first presents the proposed model of location problem in section 2 . Section 3 presents the implementation of the proposed model for a real-world case study of dairy product and concluding remarks are given in section 4.

\section{The proposed model}

There are literally different parameters involved to locate an appropriate facility layout such as the availability of the necessary infrastructure, the weather condition, etc. The other issue involving the criteria is to determine a precise value of each criterion and we may not often be able to find out an exact value for them. One alternative solution is to use different multi criteria decision making method or to implement fuzzy numbers in terms of triangular or other forms.

The proposed model of this paper determines different important criteria, which are involved with locating a food production facility. There are five main factors influencing the facility location, which includes access to natural water, electricity, natural gas, roads, telecommunication and waste disposal. The other items of different cost components, workforce, business conditions and quality of life are the other important factors influencing facility layout. Table 1 shows the details of the criteria for a typical facility layout.

\section{Table 1}

The necessary criteria affecting the facility location

\begin{tabular}{ll}
\hline Main criteria & Sub-criteria of the main criteria \\
\hline Utility & $\begin{array}{l}\text { Access to natural water, electricity, natural gas, road communications, telecommunications, waste } \\
\text { disposal }\end{array}$ \\
Costs & $\begin{array}{l}\text { Cost of water, electricity, gas, telecommunications, waste disposal, transport, land and construction } \\
\text { Work force }\end{array}$ \\
$\begin{array}{l}\text { Business } \\
\text { conditions }\end{array}$ & $\begin{array}{l}\text { Access to skilled and unskilled labor, labor costs, labor education special programs } \\
\text { sales }\end{array}$ \\
Quality of life & $\begin{array}{l}\text { Cultural level, health level, the amount of schools and universities, Habitat capability, house making } \\
\text { costs, cultural opportunities, recreational opportunities, health facilities, weather conditions }\end{array}$ \\
\hline
\end{tabular}

According to Table 1, there are over 30 sub-criteria influencing the facility layout and we may not be able to consider all of them because of the limitation on time and research budget. Therefore, we first choose some of the most important factors summarized in Table 2.

\section{Table 2}

Selected criteria to locate the factory

\begin{tabular}{ll}
\hline Main criteria & Selected sub-criteria \\
\hline Accesses & Access to natural water, electricity, natural gas, road communication \\
Costs & Cost of water, electricity, gas, transportation \\
Work force & Access to skilled and unskilled labor, labor costs \\
Business conditions & $\begin{array}{l}\text { Access to raw material resources, access to markets, tax-free sales } \\
\text { Quality of life }\end{array}$ \\
$\begin{array}{l}\text { Cultural level, the amount of schools and universities, Habitat capability, The cost of building } \\
\text { houses, the cost of making houses, cultural opportunities, recreational opportunities, health } \\
\text { facilities, weather conditions }\end{array}$ \\
\hline
\end{tabular}


Based on the information of this table, access to natural water, electricity, natural gas and road communication are some of the most important factors. The utility cost such as gas and electricity are some of the important cost items. The important workforce includes the access of unskilled and skilled labors and the cost of hiring people. There are different rules and regulations associated with each items involved with our study and we summarize them in Table 3.

\section{Table 3}

Environmental laws and regulations for locating food industry

Laws and regulations

The unit must have at least $3 \mathrm{~km}$ distance from cement factories, $0.5 \mathrm{~km}$ from health and make-up industries, $1 \mathrm{~km}$ from pharmaceutical, $2 \mathrm{~km}$ from animal industries and $2 \mathrm{~km}$ from the other factories of services and industries.

The unit must be at least 350 meters away from the second-class contaminants (molding, mosaic and ceramic making, cemeteries, industrial slaughterhouses).

It must have a minimum distance of $1 \mathrm{~km}$ from the first-class contaminants (poultry, livestock, industrial slaughterhouses, factories, fertilizer or waste accumulation center, tanning, leather, hide, sewage treatment).

The food producer must be at least 500 meters away from the villages where there are livestock and poultry to the traditional way in residential buildings.

It must be at least three kilometers away from the residential area and outside of town.

Based on the rules and regulation given in Table 3 we realize that we do not have much control on some of the items given in Table 2 as decision criteria. Therefore, we can reduce some of the conditions based on the rules and the regulation. Next we divide the most important factors into two groups where the first group is associated with the criteria such as the closeness to the raw materials, target market and transportation cost. The second group is also involved with other important factors such as the infrastructure, living conditions, etc. Table 4 shows all these two group items.

\section{Table 4}

The classification of two criteria for locating the food production unit

\begin{tabular}{ll}
\hline Group & Criteria \\
\hline First & access to raw materials, markets and transport costs \\
Second & $\begin{array}{l}\text { energy resources and ways of communication, the cost of energy resources, access to labor, labor costs, tax- } \\
\text { free sales and the quality of life }\end{array}$ \\
\hline
\end{tabular}

Note that the regulation and the available data are not precisely available and we may not make a suitable decision solely based on the uncertain data. Therefore, we propose to use a fuzzy multi criteria decision making problem for some of the uncertain data to handle uncertainty for our case study. The fuzzy numbers are defined as a triangular form as follows,

$\mu(d)=\left\{\begin{array}{cc}\frac{n-d}{n-m} & m \leq d \leq n \\ 0 & \text { otherwise }\end{array}\right.$

where $d$ is the criteria in fuzzy form, $\mu$ is the membership function and $n$ and $m$ are the maximum and the minimum limits of the fuzzy criteria, respectively. Zadeh (1983) in one his artworks explained how to use fuzzy logic to handle uncertainty. He emphasized that the management of uncertainty is an important problem in the design of expert systems since much of the input data in the knowledge base of a typical expert system is unreliable or imprecise. The uncertainty could be expressed as fuzzy numbers or in the forms of linguistic words (Zadeh, 2000).

The proposed model of this paper maximizes the sum of desirability of all input data subject to some bound constraints. Let $(x, y)$ and $\left(a_{i}, b_{i}\right)$ be the coordination of the place where a plant needs to be located and the coordination of market sales and livestock, respectively. We want to find a suitable place where weighted Euclidian norm is minimized and some bound constrains hold. Therefore, we have, 
$\min \sum_{i=1}^{n} w_{i} \sqrt{\left(x-a_{i}\right)^{2}+\left(y-b_{i}\right)^{2}}$

subject to

$l \leq \sqrt{\left(x-a_{i}\right)^{2}+\left(y-b_{i}\right)^{2}} \leq u$

For the implementation of the proposed model of this paper, we use Euclidean norm to compute the distance between an alternative and an attribute. We choose only two alternatives $w_{1}$ and $w_{2}$ associated with two group criteria where $w_{1}$ and $w_{2}$ represent the weights of the importance for the access to raw materials and market sales, respectively.

The implementation of our proposed model (2) first finds the coordination and an alternative place and then it replaces the final solution in Eq. (1) to see how good the solution fits into our numbers.

\section{Case study}

The proposed model of this paper is implemented for one of the Iranian cities called Gorgan located in north part of Iran and it is the capital city of a province called Golestan. As of 2005, the city has a population of 241,000 people covering an area of about 1,700 square kilometers.

We plan to setup a food producer unit in this province based on the criteria discussed in section 2. The first step to locate the suitable site is to find the importance of the each criterion. One alternative to find suitable weights for each criterion is to use analytical hierarchy procedure (AHP). This method helps us compare each pair of criteria and assign a value for the relative importance of one against the other one. We use Likert (1932) numbers from one to nine where one represents no difference between two choices and 9 means that one is strongly preferred to other one. Table 5 summarizes the results of our pairwise comparison where the first column shows the main criteria and the weight associated with each criterion is reported on the second column of the table. The other two columns of the table also show the details of the weight for each sub-criterion. From table 5 we can understand that the access to different resources plays the most important role on assessing a location problem. Business condition and cost, which include the access and cost of reaching the business market, are the second most important items.

\section{Table 5}

The results of pairwise comparison

\begin{tabular}{|c|c|c|c|}
\hline Main criteria & Weight & The sub- criteria & Weight \\
\hline \multirow{5}{*}{ Access } & \multirow{5}{*}{0.40} & Access to natural water & 0.28 \\
\hline & & Access to Electricity & 0.30 \\
\hline & & Access to natural gas & 0.06 \\
\hline & & Access to waste disposal & 0.34 \\
\hline & & Access to the path of communication & 0.02 \\
\hline \multirow{4}{*}{ Costs } & \multirow{4}{*}{0.26} & Cost of natural water & 0.54 \\
\hline & & Electricity costs & 0.26 \\
\hline & & Natural gas costs & 0.14 \\
\hline & & Shipping costs & 0.06 \\
\hline \multirow{3}{*}{ Workforce } & \multirow{3}{*}{0.05} & Availability of skilled labor & 0.77 \\
\hline & & Availability of non- skilled labor & 0.15 \\
\hline & & Labor costs & 0.08 \\
\hline \multirow{3}{*}{ Business conditions } & \multirow{3}{*}{0.26} & Access to markets and customers & 0.53 \\
\hline & & Access to raw materials & 0.36 \\
\hline & & Sales tax exemption & 0.11 \\
\hline \multirow{8}{*}{ Quality of life } & \multirow{8}{*}{0.03} & Climate & 0.1 \\
\hline & & Cultural level & 0.21 \\
\hline & & Access to educational facilities & 0.26 \\
\hline & & Habitat capability & 0.14 \\
\hline & & Housing construction costs & 0.08 \\
\hline & & Health Facilities & 0.10 \\
\hline & & Recreational opportunities & 0.07 \\
\hline & & Cultural opportunities & 0.03 \\
\hline
\end{tabular}


As we explained earlier, some of the parameters involved with locating a unit are under uncertainty and we plan to use fuzzy technique to find suitable value of each parameter. Table 6 presents details of the fuzzy numbers.

\section{Table 6}

The input numbers of uncertain parameters

\begin{tabular}{lcc}
\hline Title & $n$ & $m$ \\
\hline The relative distance from the water resources & 2 & 10 \\
The relative distance from the hydro(electricity and Gas) & 100 & 2000 \\
The relative distance from roads & 150 & 2000 \\
The accessibility to workforce & 5000 & 30,000 \\
The accessibility to raw materials & 1000 & 150,000 \\
The accessibility to target market & 5000 & 300,000 \\
The quality of life & 5000 & 50,000 \\
\hline
\end{tabular}

Our survey indicates that there are only a limited number of market sale available and the centers of these units are summarized in Table 7.

\section{Table 7}

The coordination of available market sales

\begin{tabular}{cccc}
\hline Market \#1 & Market \#2 & Market \#3 & Market \#4 \\
\hline$(271092,4080395)$ & $(242112,4076610)$ & $(309933,4086726)$ & $(273839,4098954)$ \\
\hline
\end{tabular}

In addition, Table 8 summarizes the centers of livestock facilities. As we can observe from Table 8 there are 18 different places to the facility location of our case study.

\section{Table 8}

The coordination of available livestock facilities

\begin{tabular}{lllll}
\hline Livestock \#1 & Livestock \#2 & Livestock \#3 & Livestock \#4 & Livestock \#5 \\
$(275500 ‘ 4086500)$ & $(253600,4080600)$ & $(253200,4075950)$ & $(253200,4073350)$ & $(251100,4083600)$ \\
Livestock \#6 & Livestock \#7 & Livestock \#8 & Livestock \#9 & Livestock \#10 \\
$(232500,4075100)$ & $(233500,4076600)$ & $(241850,4078100)$ & $(242450,4075000)$ & $(250700,4078150)$ \\
Livestock \#11 & Livestock \#12 & Livestock \#13 & Livestock \#14 & Livestock \#15 \\
$(300400,4088200)$ & $(304400,4094500)$ & $(308400,4097100)$ & $(256000,4100900)$ & $(272500,4101400)$ \\
Livestock \#16 & Livestock \#17 & Livestock \#18 & & \\
$(273600,4106900)$ & $(279300,4098600)$ & $(304800,4086200)$ & & \\
\hline
\end{tabular}

The implementation of the proposed model given in Eq. (2) using the input information of Table 7 and Table 8 with $w_{1}=0.36, w_{2}=0.54$ yields an optimal coordination of $x^{*}=(265012.1,4085730)$.

\subsection{Sensitivity analysis}

It is an interesting idea to see how well the solution of the proposed model fits to our uncertain numbers given in terms of fuzzy numbers in Table 6. As we explained earlier, the solution must be located near the transportation roads. The membership function of this point for water resources is calculated as $\mu(d 1)=0$ which means the alternative solution has a weak access to this criterion. The membership functions for utility, electricity and gas, are $\mu(d 2)=\mu(d 3)=0.78$, which mean good access to electricity and gas. Since the coordination of the proposed model is only 500 meters away from the road, we have $\mu(d 4)=0.81$ which means the alternative layout is suitable to our ideal solution. The alternative layout is only 6500 meters away from the closest city, which yields $\mu(d 5)=0.94, \mu(d 6)=0.96$ leading us to a conclusion that the alternative is very close to the city, increasing the chance of having better life style and workforse. In addition, $\mu(d 5)=0.96$ which means the quality of life is excellent. 
We have also tried to use different weights for $w_{1}$ and $w_{2}$ to see the changes on the optimal alternative. When $w_{1}=w_{2}=0.33$ we get $x^{*}=(262756.7,4085157)$ and this solution yields a weak access to water resources, electricity and gas since $\mu(d 1)=\mu(d 2)=\mu(d 3)=0$. Obviously, the new alternative is not as good as the one we previously found. However, the alternative solution yields $\mu(d 4)=0.54, \mu(d 5)=0.98$ and $\mu(d 6)=0.99$ which means the alternative place is relatively close to final cities and it provides better quality of life.

As we can see when we change the weights, we are more concerned with distance but we decided to keep the weights and change the lower and the upper bounds in Eq. (1) to study their effects on the optimal solution. Our experiments indicated that whenever we increase the limits the model could provide better results in terms of the attributes defined in Table 4.

In the second part of our sensitivity analysis, we have changed the membership function's values to study the effects of changes on utility function. We have noticed that for small changes on membership function, e.g. 50, there is not much change of the utility function. However, once the changes increase on the order of 1000, the utility of the objective function will change, significantly.

\section{Conclusion}

In this paper, we have presented a model to determine the efficient location of a food industry. The proposed model of this paper has considered various factors influencing the location of a food industry such as vicinity to cities, transportation roads, etc. We applied the model for a real-world case study of food industry where there were different alternatives and analyzed the best possible alternative using fuzzy behavior of some the most important factors. This paper can be extended for the cases where there is more than one single objective function and we leave it for interested researchers.

\section{References}

Bindi, F., Manzini, R., Pareschi, A., \& Regattieri, A. (2009). Similarity-based storage allocation rules in an order picking system: An application to the food service industry, International Journal of Logistics Research and Applications, 12 (4), 233-247.

Drira, A., Pierreval, H., \& Hajri-Gabouj, S. (2007). Facility layout problems: A survey. Annual Reviews in Control, 31(2), 255-267.

Dweiri, F. (1999). Fuzzy development of crisp activity relationship charts for facilities layout. Computers \& Industrial Engineering, 36(1), 1-16.

Grobelny, J. (1987). The fuzzy approach to facilities layout problems. Fuzzy Sets and Systems, 23(2), 175-190.

Huda, A. M., \& Chung, Ch. A.(2002). Simulation modeling and analysis issues for high-speed combined continuous and discrete food industry manufacturing processes. Computers \& Industrial Engineering, 43(3), 473-483.

Jin, S., \& Tokunaga, S. (2007). Location of Japanese investment in China's food industry. China Review, 7 (1), 129-138.

Likert, R. (1932). A Technique for the Measurement of Attitudes. Archives of Psychology, 140, 1-55.

Oppen, M. V., \& Ryan, J. G. (1985). Research resource allocation: determining regional priorities. Food Policy, 10(3), 253-264.

Singh, S.P., Singh, V.K. (2011). Three-level AHP-based heuristic approach for a multi-objective facility layout problem. International Journal of Production Research, 49 (4), 1105-1125.

Van Donk, D. P., \& Gaalman, G. (2004). Food safety and hygiene: systematic layout planning of food processes. Chemical Engineering Research and Design, 82(11), 1485-1493.

Zadeh , L. A. (1983). The role of fuzzy logic in the management of uncertainty in expert systems. Fuzzy Sets and Systems, 11(1-3), 197-198.

Zadeh, L. A. (2000). Outline of a computational theory of perceptions based on computing with words. Soft Computing and Intelligent Systems, 3-22. 